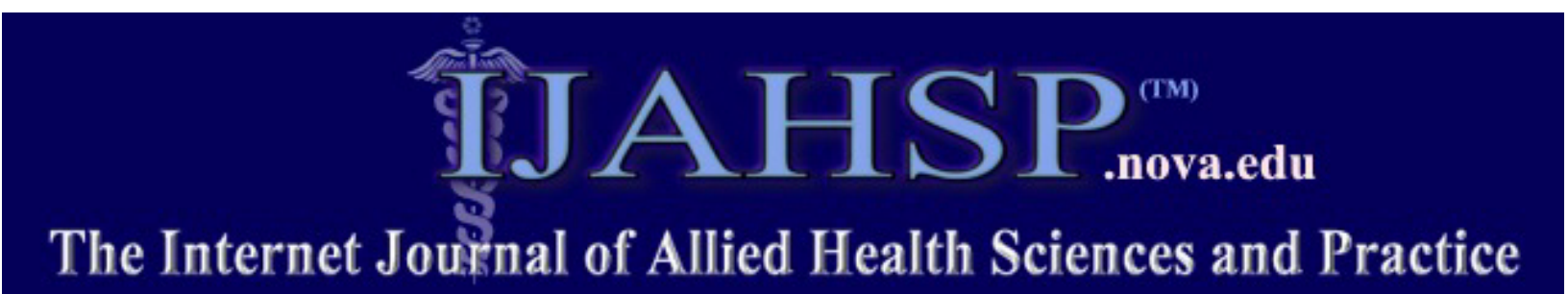

A Peer Reviewed Publication of the College of Health Care Sciences at Nova Southeastern University

Dedicated to allied health professional practice and education

http://ijahsp.nova.edu Vol. 10 No. 4 ISSN 1540-580X

\title{
Determining Cognitive and Non-Cognitive Predictors of Success on the National Physical Therapy Examination
}

\author{
Carolyn Galleher, PT, DHS 1 \\ Peter J. Rundquist, PT, $\mathrm{PhD}^{2}$ \\ David B. Barker, $\mathrm{PhD}^{3}$ \\ Wen-Pin Chang, PhD, OTR/L 4
}

1. Assistant Professor, Gannon University, Erie, Pennsylvania

2. Associate Professor, University of Indianapolis, Indianapolis, Indiana

3. Associate Professor, Gannon University, Erie, Pennsylvania

4. Assistant Professor, Creighton University, Omaha, Nebraska

United States

CITATION: Galleher C, Rundquist P, Barker D, Chang W. Determining Cognitive and Non-Cognitive Predictors of Success on the National Physical Therapy Examination. The Internet Journal of Allied Health Sciences and Practice. Oct 2012. Volume 10 Number 4.

\begin{abstract}
Background and Purpose: A variety of admission criteria have been utilized to assist in the selection of viable candidates in physical therapy programs. These criteria include cognitive measurements such as grade point average (GPA) and standardized test scores. However, only a few studies correlated these cognitive measurements to predicting success on the National Physical Therapy Examination (NPTE). The purpose of this study was to examine the performance of entry-level doctoral physical therapy (DPT) students on prior cognitive measurements and correlate it to passing on the first attempt of the NPTE. This study also aimed to determine if two inventory surveys examining personality traits and coping skills were appropriate predictors for passing the NPTE on the first attempt. Subjects: Forty-nine students from seven physical therapy programs which offer the DPT program participated in the study. Methods: Participants provided their Scholastic Aptitude Test (SAT) scores and undergraduate grade point average (GPA) and completed three surveys including a survey on past academic performance, the Big Five Inventory (BFI) personality survey and the Coping Inventory for Stressful Situations (CISS). Logistic regression and correlation coefficients were used to analyze the relationship of these factors to the NPTE and to each other. Results: SAT score was the only significant variable identified as a predictor for passing the NPTE on the first attempt. Discussion and Conclusion: SAT scores may be utilized to predict performance on the NPTE. Personality traits and coping skills were not found to be statistically significant predictors.
\end{abstract}

\section{BACKGROUND AND PURPOSE}

Physical therapy (PT) educators strive to find individuals who will be successful academically in their graduate professional programs and ultimately successful on the National Physical Therapy Examination (NPTE). Thus, they strive to select candidates who will be able to cope with the challenges of the academic rigor of graduate level work and who have the necessary personal characteristics to be successful health professionals. ${ }^{1-6}$ In order for these graduate students to become physical therapists, they must pass the state licensure examination. The primary goal for both the educators and students is success on the first attempt of the NPTE. 
Although there are published studies regarding cognitive ability and success in PT professional programs, ${ }^{1-17}$ few have focused on the relationship between cognitive ability and successful passing of the NPTE on the first attempt.10-12, 14-17 In addition, a few studies suggested that other factors such as coping skills and personality traits could have an impact on academic performance for other health-related professional programs. ${ }^{5-6}, 18-24$ However, to our knowledge, no studies have examined using personality characteristics and coping abilities as prediction of success on the NPTE.

A variety of PT program admission criteria have been analyzed, including undergraduate grade point average (GPA), Scholastic Aptitude Test (SAT) scores, American College Test (ACT) scores, Graduate Record Exam (GRE), foundational science GPA, interview scores, essays, and Allied Health Profession Admission Test (AHPAT) scores to assist in the selection of viable candidates for physical therapy programs.1-17,25-27 Most studies have looked at admission criteria to predict academic performance within the professional programs previously at the undergraduate level or more current literature analyzing criteria for graduate level programs. ${ }^{1-13}$ Only a few studies were found which correlated admission criteria to prediction of performance on the NPTE. 10-12,14-17 Roehrig concluded that standardized ability tests, i.e. ACT, and GPA are the most practical criteria to predict scores on the NPTE. ${ }^{11} \mathrm{~A}$ study by Utzman et al investigated whether undergraduate GPA, GRE scores, and race/ethnicity can determine performance on the NPTE and risk for failing the NPTE in a sample of 20 graduate level PT programs. ${ }^{14}$ The PT programs were eligible to participate if they used the GRE score in their admission criteria and had estimated class size of at least 30 students per year for the graduating classes of 2000 to 2004 . The researchers sampled programs which were composed of MPT and DPT curriculum. Programs were targeted from the four regions of the United States (US) including the Northeast, Midwest, South, and West.8,14 The researchers found a higher pass rate on the NPTE for white/non-Hispanics, those with undergraduate GPAs of 3.49 or higher, and GRE scores that exceeded 400 points (scale of $200-800$ points with 10 point increments) and 530 points on the verbal and quantitative portions, respectively.

Other variables including interviews, essays, and personality inventories have been suggested as possible important factors for determining success in professional PT programs. $5,6,18-24,26-27$ However, only one of the above studies examined how these variables directly affected performance on the NPTE. Hollman et al evaluated the use of personal behavioral interviews as part of the PT admission process. ${ }^{17}$ The behavioral interview consisted of the following subject matter: how students maintained objectivity when faced with problem situations in which they were emotionally involved, interaction with people with different values from their own, communication skills, listening skills, and working as a team. To improve face validity of the interview, the researchers selected items which were consistent with the values of the generic abilities accepted by PT educators as necessary for student physical therapists (SPTs). The authors concluded that performance on the behavioral interview as measured on a 5point Likert-type scale along with the verbal GRE score assisted with prediction of the NPTE score. These studies indicate that using personality measurements may be beneficial to predict student success in professional PT programs and on the NPTE.

Besides using personality measurements, it may be beneficial to evaluate a student's ability to cope with the stresses of graduate level education. Frazer and Echternach identified that stress could lead to poor academic performance in SPTs. ${ }^{28}$ In their study, students were given three stress assessment instruments including the Academic Stress Scale, Student Stress Scale, and Freedom from Compulsion Scale. They concluded that PT education causes stress for many SPTs and students need to have the resources available to mediate and moderate these stressful conditions. ${ }^{28}$

Therefore, the purpose of this study was to evaluate the specific cognitive measurements reported by students of DPT programs including undergraduate GPA and SAT scores to estimate performance on the NPTE. This study also aimed to determine if two proposed inventory surveys, Big Five Inventory (BFI) and Coping Inventory for Stressful Situations(CISS), which examine personality traits and coping skills, could be utilized to predict performance on the NPTE.

The research hypothesis for this study is that higher scores on the cognitive measurements of SAT and undergraduate GPA as well as higher scores on the non-cognitive measurement of the personality trait of conscientiousness and the coping skill of taskoriented coping strategy will be useful to predict the probability of passing on the first attempt of the NPTE.

\section{METHODS}

\section{Participants}

This study surveyed students from seven PT programs which offer the DPT. These programs are similar in size and located in the mid-west to eastern portion of the US. These programs are all accredited by the Commission on Accreditation in Physical Therapy Education. All seven DPT programs are $7-8$ semesters in length with $36-40$ weeks of clinical rotations distributed throughout the curriculum. Enrollment across the programs range from $30-50$ students accepted annually. All of the prerequisite courses and GPA requirements for admission are similar. The curriculums in all seven programs are based on the Normative Model of PT Professional Education 
This research study was approved by the University of Indianapolis Institutional Review Board (IRB) and by the Gannon University IRB. Surveys were mailed to 270 students in the spring semester of 2010 . Sixty-one students $(23 \%)$ returned the signed consent forms and survey information. However, only 49 students completed all survey information and therefore could be included in the data analysis. Portney and Watkins report that response rates for surveys between $60 \%$ and $80 \%$ is considered excellent. ${ }^{29}$ However, they report realistically, a response rate between $30 \%$ and $60 \%$ is a more expected return rate. The low return rate on this study could affect its external validity or ability to demonstrate a representation of the student population as a whole. Demographic information of the individual students was not reported and survey information was deidentified and therefore could not be linked to individual programs.

\section{Instrumentation}

Graduating students from each university were surveyed on their prior academic performance through a written questionnaire including SAT score, ACT score, GRE score, high school and undergraduate GPA, foundational sciences grades, and number of semesters completed. Two GPAs were reported by the students: undergraduate GPA and current professional GPA. This study analyzed undergraduate GPA in an attempt to have a standardized score for comparison. Pre-requisite GPA was not reported since the programs may have differences in which courses are included in the calculation of the pre-requisite GPA. Surveys were completed prior to graduation; therefore, graduate GPA could not be utilized. First year GPA was not included since two of the DPT programs utilized a competency-based approach which means students are allowed to retake an examination if they initially do not meet the competency level determined by the program. It was not possible to obtain first year GPAs which would be comparable for all programs.

They also filled out two psychological inventory forms: BFI (Appendix 1) and CISS. These self-reported inventories were recorded along with success on passing the NPTE on the first attempt, which was self-reported upon participants receiving their NPTE results. The BFI is a 44 item questionnaire to assess the five main dimensions of personality, including Extraversion, Agreeableness, Conscientiousness, Emotional Stability versus Neuroticism, and Openness. ${ }^{30}$ Extraversion refers to an individual's ability to be sociable, assertive, energetic, outgoing, and enthusiastic. Agreeableness refers to social and caring behaviors including sympathetic, kind, appreciative, and trusting. Conscientiousness refers to behaviors which are task-oriented including organized, thorough, responsible, and reliable. Neuroticism is the only negative trait and is described as the tendency to experience anxiety with descriptors including tense, anxious, nervous, and moody. The final dimension is Openness which refers to an individual who has wide interests, who is imaginative, intelligent, and insightful. ${ }^{30}$ The BFI is frequently used in research studies because it is a less expensive tool and easily obtainable for public distribution and use compared to other personality inventory tools. The BFI has an internal consistency reliability of coefficient alpha 0.83 .30 The reliability of the BFI ranges from a coefficient alpha of $0.79-0.88$ for each category. ${ }^{30}$ Each has a standardized validity coefficient of $0.90-0.94 .{ }^{30}$ Specifically, the reliability of conscientiousness has a coefficient alpha of .82 and a standardized validity coefficient of 0.92 .30

The BFI scoring scale correlates specific questions to each of the five personality dimensions. The value for conscientiousness is based on adding the responses of 9 designated statements from the BFI survey. Although prior studies suggest certain personality characteristics may be indicative of better academic performance, there are no studies which define the specific personality traits of student physical therapists (SPTs) who are academically successful in graduate DPT programs. However, examining personality characteristics of other health professions may assist in determining characteristics which would demonstrate academic success for the SPT. Ferguson et al examined the role of personality in performance of students in medical training. ${ }^{19}$ The researchers found that the personality trait of conscientiousness is strongly associated with levels of success in medical training. This is the basis for why in this study conscientiousness will be used as the characteristic which may be predictive of success on the NPTE.

The CISS is a 48 item questionnaire designed to assess the basic dimensions of coping: task, emotion, and avoidance-coping. Task coping is defined as individuals who use behavioral or cognitive problem-solving techniques when dealing with stressful situations. Emotion oriented coping is when an individual responds to stress with emotional outbursts and are self-preoccupied. Avoidance coping refers to use individuals who distract themselves or rely on social supports to deal with stress. ${ }^{31-32}$ The CISS has good construct and concurrent validity and is also a reliable measurement of coping skills. The internal consistency reliability ranges from a coefficient alpha of $0.83-0.92$ for adults using the CISS. Specifically, task coping has a coefficient alpha of 0.92 for adult males and 0.90 for adult females. ${ }^{32}$ The value for task-coping skills was determined by adding the responses of 16 designated items on the CISS which are the task oriented coping responses. They include the scoring of responses to statements indicating how much an individual engages in particular types of activities when encountered with a stressful situation such as scheduling time better, analyzing the problem better before reacting, and coming up with different solutions to the problem. ${ }^{32}$ 
There are no published studies evaluating the coping skills of SPTs for different stresses. Yet, other professions have examined coping skills in their professional students. For example, Adejumo and Brysiewicz evaluated the coping strategies of nursing students in a problem-based professional program. ${ }^{24}$ They used the COPE inventory tool which measures three dimensions of coping: problem-focused, emotion-focused, and dysfunctional strategies. Results revealed that students primarily used problemfocused coping skills followed by emotion-focused coping skills in order to be successful in their professional program. The COPE inventory tool was not used in this current study but the Coping Inventory for Stressful Situations (CISS) also measures similar dimensions of coping was used. It is a less expensive tool and easily obtainable for public distribution; therefore, it was used in this study.

\section{Procedure}

Program directors were contacted by the study investigator explaining the current study and asking if the universities would distribute these surveys to their students in their final year of graduate school. Specific instructions to the program directors were given both verbally and through email contact including how to distribute the surveys and the director's instructions to the students. All program directors agreed to distribute the surveys.

Individual packets containing a cover letter, informed consent, three survey forms, a contact form/postcard to contact the students after graduation and a postage-paid return envelope were sent to the program directors. These packets were distributed by the program directors. It was emphasized to the students by the program directors that this was completely voluntary and had either no reflection on student performance at their institution or no impact on student grades. All students who agreed to participate signed an informed consent and filled out the three surveys and the contact information card. The informed consent indicated the investigator's name and contact information if the participants had any questions, and explained the process to withdraw from the study at any time. The individual students mailed the forms back to the research assistant using the postage paid envelope. No further attempt was made to solicit student participation. Only those students who completely filled out the surveys were included in the study. No incentives were offered to the participants.

Each survey had an assigned number which was used for de-identifying the survey participants. The postcards also had the same assigned number. The student's address and assigned number were separated from the surveys when they were returned by a research assistant so that the researcher was blinded to the participants' names. After graduation, an additional survey was sent to all students asking them to indicate if they passed the NPTE on the first attempt. The data was reviewed by the investigator when surveys were returned.

Some of the institutions preferred that students were contacted via e-mail. All forms including the cover letter, survey forms, follow-up postcard with address after graduation, and consent letter were electronically sent to the program chair who forwarded it to the students' e-mail addresses. A return postal address was given to the participants to send their completed survey forms and signed informed consent. Postage paid return envelopes were mailed to the program directors if the students who received the e-mailed forms wanted to use these envelopes to return their informed consent forms, postcard, and surveys. The return surveys were given to the research assistant who separated all identified information from the surveys. The assigned number was placed on the surveys prior to the investigator reviewing the information. A postal address was requested to contact the participant after graduation for the follow-up NPTE survey which also was kept by the research assistant.

\section{DATA ANALYSIS}

The data were analyzed with the software SPSS 16.0 Statistical Package for the Social Sciences (IBM, Chicago, IL). A hierarchical forward stepwise logistic regression was used to analyze the data. Binary logistic regression is used when predictor variables are qualitative or quantitative and the criterion variable is dichotomous (pass or not pass the NPTE on the first attempt). ${ }^{33}$ The independent variables included undergraduate GPA, SAT score (combined math and reading scores), inventory scores from BFI for conscientiousness, and CISS inventory score for task-oriented coping. The cognitive scores of undergraduate GPA and SAT were used because they were the scores most consistently reported by the participants. Based upon the evidence, conscientiousness and task-oriented coping were the best variables to be associated with academic performance. The hierarchical logistic regression was used because prior evidence suggested that GPA and SAT scores (step 1) were established predictors whereas the scores on the BFI and CISS (step 2) were only speculative. A correlation matrix was used to further evaluate the relationships between the variables.

\section{RESULTS}

\section{Descriptive Statistics}

Of the 61 participants in this study, 49 were used in the statistical analysis. Twelve participants had incomplete data. Summary of the descriptive statistics of pre-admission variables are listed in Table 1. Forty-four out of the 49 students passed on the first 
attempt of the NPTE which is an $89.8 \%$ pass rate. The mean scores reported for each of the variables were SAT 1158 points, undergraduate GPA 3.55, conscientiousness score of 36 points, and task-coping score of 60 points.

Table 1. Descriptive Statistics

\begin{tabular}{|c|c|c|c|c|c|}
\hline & $\mathrm{N}$ & Mean & SD & Pass & Fail \\
\hline SAT & 49 & 1158.37 & 127.90 & ---- & ---- \\
\hline ugGPA & 49 & 3.55 & .271 & ---- & --- \\
\hline Cons & 49 & 36.27 & 5.15 & ---- & ---- \\
\hline Task & 49 & 59.57 & 8.49 & ---- & --- \\
\hline NPTE & 49 & - & - & 44 & 5 \\
\hline
\end{tabular}

SAT: Scholastic Aptitude Test

ugGPA: undergraduate grade point average

Cons: conscientiousness

Task: task coping

NPTE: National Physical Therapy Examination

\section{Prediction of Passing on the First Attempt of the NPTE}

The results of the hierarchical forward stepwise logistic regression are presented in Table 2. The chi-square goodness of fit score is 17.224 with 1 degree of freedom and $p<.001$. Cox and Snell $R$ Square was .296 which suggested the equation provides weak to modest predictive utility. SAT score was the only statistically significant predictor for passing on the first attempt of the NPTE $p$ $=.012(p<.05)$. Conscientiousness, undergraduate GPA and task-coping were not significant predictors for passing the NPTE on the first attempt. A backward regression was also run and similar results were found. SAT was the only significant predictor. Utilizing SAT scores increased the ability to predict if a student will pass on the first attempt of the NPTE by $4.1 \%$. SAT scores increased the percentage of correctly determining pass rate from $89.8 \%$ to $93.9 \%$ with an odds ratio of 1.031 (Table 2). Figure 1 describes the equation used in predicting probability of an individual to pass on the first attempt of the NPTE.

Table 2. Logistic Regression Summary

\begin{tabular}{|r|c|c|c|c|c|c|}
\hline & $\begin{array}{c}\text { Beta } \\
\text { Coefficient }\end{array}$ & $\begin{array}{c}\text { Standard } \\
\text { Error }\end{array}$ & $\begin{array}{c}\text { Wald } \\
\text { Test }\end{array}$ & $\begin{array}{c}\text { Degrees } \\
\text { of } \\
\text { Freedom }\end{array}$ & p-value & Odds Ratio \\
\hline SAT & .031 & .012 & 6.301 & 1 & .012 & 1.031 \\
\hline Constant & -30.922 & 12.796 & 5.840 & 1 & .016 & .000 \\
\hline
\end{tabular}

SAT: Scholastic Aptitude Test

Figure 1. Equation 1: Calculation of Probability

Probability (pass rate $)=\underline{\exp (-30.922+.031 \mathrm{SAT})}$

$1+\exp (-30.922+.031 \mathrm{SAT})$

A correlations matrix is displayed in Table 3. NPTE and SAT were correlated with a Spearman's rho correlation coefficient of $0.46(p=.001)$ and with undergraduate GPA with a correlation coefficient of $0.301(p=.036)$. A Spearman's rho was used because the correlation to the NPTE is a point biserial correlation. A correlation between conscientiousness and undergraduate GPA was also seen with a Spearman's rho correlation coefficient of $0.437(p=.002)$ and between conscientiousness and taskcoping with a correlation coefficient of $0.35(p=.014)$. All other correlations were not significant. 
Table 3. Nonparametric Correlation Using Spearman's Rho

\begin{tabular}{|c|c|c|c|c|c|c|}
\hline & & NPTE & SAT & ugGPA $^{1}$ & cons & task coping \\
\hline \multirow[t]{2}{*}{ NPTE } & Correlation Coefficient & 1.000 & $.458^{* *}$ & $.301^{*}$ & .086 & -.024 \\
\hline & Sig. (2-tailed) & & .001 & .036 & .557 & .871 \\
\hline \multirow[t]{2}{*}{ SAT } & Correlation Coefficient & $.458^{* *}$ & 1.000 & .263 & .042 & .152 \\
\hline & Sig. (2-tailed) & .001 & & .068 & .776 & .296 \\
\hline \multirow[t]{2}{*}{ ugGPA } & Correlation Coefficient & $.301^{*}$ & .263 & 1.000 & $.437^{* *}$ & -.078 \\
\hline & Sig. (2-tailed) & .036 & .068 & & .002 & .596 \\
\hline \multirow[t]{2}{*}{ conscientious } & Correlation Coefficient & .086 & .042 & $.437^{*+}$ & 1.000 & $.350^{*}$ \\
\hline & Sig. (2-tailed) & .557 & .776 & .002 & & .014 \\
\hline \multirow[t]{2}{*}{ task_coping } & Correlation Coefficient & -.024 & .152 & -.078 & $.350^{*}$ & 1.000 \\
\hline & Sig. (2-tailed) & .871 & .296 & .596 & .014 & \\
\hline
\end{tabular}

NPTE: National Physical Therapy Examination

SAT: Scholastic Aptitude Test

ugGPA: undergraduate grade point average

A 95\% confidence interval was calculated for the four independent variables as they correlate to the NPTE using the correlation coefficients. The confidence interval ranges for SAT and undergraduate GPA were correlated to the NPTE. The confidence interval ranges for conscientiousness and task coping were not correlated to the NPTE. (Table 4)

Table 4. 95\% Confidence Intervals

\begin{tabular}{|l|c|c|}
\hline & Lower range & Higher range \\
\hline Conscientiousness & -0.2 & .358 \\
\hline Task coping & -.303 & .258 \\
\hline Undergraduate GPA & .022 & .536 \\
\hline Scholastic Aptitude Test (SAT) & .203 & .654 \\
\hline
\end{tabular}

\section{DISCUSSION}

This study hypothesized four variables (SAT, undergraduate GPA, conscientiousness, and task-coping) could be utilized as predictors for passing on the first attempt of the NPTE. The results of this study demonstrated that only one of these variables, SAT score, was statistically significant for predicting performance on the NPTE. The first time pass rate was $89.8 \%$ in this student sampling. This is higher than the current national average of passing on the first attempt as reported by the Federation of State Boards of Physical Therapy (FSBPT). ${ }^{34}$ The first time pass rate for students who graduated in 2009 was $88 \%$. Having a sampling of students who overall scored lower than the national average may have an effect or alter the current findings in this study.

SAT score was found to be a variable which can predict the ability of a student to pass on the first attempt of the NPTE. This is consistent with prior studies which found standardized test scores are good for predicting passing on the first attempt of the NPTE. 10-11,14-15,17 Prior studies have found that ACT scores and GRE scores were predictors of pass rate on the NPTE. 10-11,14-15, 17 This study, however, used SAT scores because this was the most prevalent score reported by students. GRE and ACT scores were reported less than $50 \%$ of the time on the academic performance surveys. The SAT is a standardized test used to assess a student's aptitude. ${ }^{35}$ There is significant controversy over the ability of SAT to predict performance due to gender, race, and 
socioeconomic bias. $35-39$ However, race and socioeconomic factors were not factors examined in this current study. Analysis of gender demonstrated that $78 \%$ of the students were female compared to $22 \%$ male. Because SAT only increased $4.1 \%$ pass rate of the NPTE in the present study, and GRE and ACT were not included, the relationship between performance on the NPTE and performance on other standardized tests could be further examined.

Undergraduate GPA was not a statistically significant predictor of performance on the NPTE in this study. However, prior studies have found that a variety of GPAs could be statistically significant predictors including pre-requisite GPA, overall undergraduate GPA, overall graduate GPA and GPA after the first year of graduate school.12,14,15 This study analyzed only undergraduate GPA in an attempt to have a standardized score for comparison since more than one program was included in the current study. In a study by Dockter, first year professional GPA was the best predictor for performance on the NPTE.12 Dockter was able to utilize this variable since all participants attended the same PT program. Thieman, Weddle, and Moore reported professional GPA was the best predictor for NPTE score with prior preadmission GPA and GRE combined demonstrated only a weak predictor for performance on the NPTE. ${ }^{10}$ Again, Thieman's participants were all from one PT program. Utzman, Riddle, and Jewell utilized hierarchical logistic regression and developed a prediction equation that included undergraduate GPA, verbal GRE, quantitative GRE, and race/ethnicity as factors for predicting performance scores on the NPTE. ${ }^{14}$ They concluded that the combination of these variables could be utilized as predictors; however, the individual PT program itself was an important predictor in the model; therefore, programs need to develop their own "measurable guidelines for identifying students who may be at risk for failing the NPTE." ${ }^{14}$ Furthermore, their results revealed that the pass rate on the NPTE varied by programs. ${ }^{14}$ For example, undergraduate GPA alone contributed to prediction of NPTE failure in only one program, and the verbal GRE alone was the most consistent predictor of NPTE performance for 9 out of the 20 programs. The current study was attempting to determine if there are common admission criteria which can be utilized by all programs to predict performance on the NPTE since the NPTE is a standardized test taken by all students regardless of which PT program they have attended. As Utzman points out, the variability between programs such as the grading scale used to factor GPA may have an effect on the ability to use GPA.

This study hypothesized that non-cognitive measurements could be utilized for prediction of passing on the first attempt of the NPTE. Statistical analysis demonstrated no statistical significance for these non-cognitive measurements from scores on the BFI for conscientiousness or from scores on the CISS for task-coping skills to predict passing performance on the NPTE. No studies have utilized personality measurement scores or coping skills scores as a predictor for licensure performance. Prior studies have correlated personality and coping skills with academic performance in health professional programs. ${ }^{19-24}$ This present study attempted to determine if there was a correlation between personality and coping skill with performance on the NPTE; however, no significant associations were discovered between these variables and performance on the NPTE. A correlation between undergraduate GPA and conscientiousness in the present study was demonstrated, which indicates a possible relationship that a student who is more conscientious would have a higher GPA.

Limitations with this study include a low response rate, under-representation of students who did not pass, and that responses were based upon the student's ability to recall scores. Obtaining the information directly from the program could insure more accurate reporting of scores. Utilizing a larger number of DPT programs may facilitate an increase in the number of participants. It would also facilitate a better representation of sampling of physical therapy students.

Future research could include a longitudinal study at a single institution examining student academic performance and coping skills from the initial decision of choosing a career in PT, tracking academic performance and skills throughout the undergraduate years, acceptance and academic performance in graduate school, and culminating in performance on the NPTE. Examining student performance over the entire academic experience may demonstrate a natural self-selection process where students who do not have the academic ability, coping skills, or personality traits are eliminated prior to applying to a graduate program.

Other studies utilizing these same variables may prove interesting. A linear regression analysis examining the relationship between SAT scores and actual scores achieved on the NPTE could be used as a predictor of performance on the NPTE. Additionally, a qualitative study describing the personality traits and coping skills of SPTs may be beneficial to establish a theoretical framework for determining personality traits and coping skills necessary for successful students in doctoral PT programs.

\section{CONCLUSION}

It is important for both the PT student and the DPT educators to ensure that PT students are successful on the NPTE. PT students cannot practice as physical therapists until they graduate from the PT programs and pass the NPTE. One of the ways that DPT programs are evaluated by CAPTE is based upon their pass rate on the first attempt of the NPTE. CAPTE sets a national standard for the first time pass rate on the NPTE and programs are compared based on the NPTE pass rate. There is 
much speculation on what are the best predictors for success in PT programs and performance on the NPTE. Results of this study concur with prior studies that performance ability on standardized tests is a predictor for success on the NPTE.

\section{REFERENCES}

1. Hayes SH, Fiebert IM, Carroll SR, Magill RN. Predictors of academic success in a physical therapy program: Is there a difference between traditional and nontraditional students? J Phys Ther Educ.1997; 11:10-16.

2. Balogun JA, Karacoloff LA, Farina NT. Predictors of academic achievement in physical therapy. Phys Ther. 1986; 66(6):976-980.

3. Scott AH, Chase LM, Lefkowitz $\mathrm{R}$, et al. A national survey of admissions criteria and processes in selected allied health professions. J Allied Health. 1995; 95-107.

4. Balogun JA. Predictors of academic and clinical performance in a baccalaureate physical therapy program. Phys Ther. 1988; 68(2)238-242.

5. Baker J. Douphrate D, Ridley D. The use of the revised PSB-Health occupations Aptitude Examinations as a predictor of success in physical therapy students. J Phys Ther Educ. 1996; 10(2):63-67.

6. Roehrig SM. Predictions of student problems in a baccalaureate physical therapy program. J Phys Ther Educ. 1990; 4(1):26-30.

7. Jewell DV, Riddle DL. A method for predicting a student's risk for academic probation in a professional program in allied health. J Allied Health. 2005; 34(1):17-24.

8. Utzman RR, Riddle DL, Jewell DV. Use of demographic and quantitative admission data to predict academic difficulty among professional physical therapy students. Phys Ther. 2007; 87(9); 1164-1180.

9. Morris J, Farmer A. The predictive strength of entering grades and biographical factors on the academic and clinical performance of physiotherapy students. Physiotherapy and Prac. 1999; 15; 165-173.

10. Thieman TJ, Weddle MI, Moore MA. Predicting academic, clinical, and licensure examination performance in a professional (entry-level) master's degree program in physical therapy. J Phys Ther Educ. 2003; 17(2): 32-37.

11. Roehrig SM. Prediction of licensing examination scores in physical therapy graduates. Phys Ther.1988; 68(5):694-698.

12. Dockter M. An analysis of physical therapy preadmission factors on academic success and scores on the national licensing examination. J Phys Ther Educ. 2001; 5(1):60-64.

13. Shiyko MP, Pappas E. Validation of pre-admission requirements in a doctor of physical therapy program with a large representation of minority students. J Phys Ther Educ. 2009; 23(2): 29-36.

14. Utzman RR, Riddle DL, Jewell DV. Use of demographic and quantitative admissions data to predict performance on the national physical therapy examination. Phys Ther. 2007; 87(9)1181-1193.

15. Kosmahl EM. Factors related to physical therapist license examination scores. J Phys Ther Educ. 2005; 19(2):52-56.

16. Riddle DI, Utzman RR, Jewell DV, et al. Academic difficulty and program-level variables predict performance on the NPTE for licensure: a population-based cohort study. Phys Ther. 2009; 89(11):1182-1191.

17. Hollman JH, Rindflesch $A B$, Youdas JW, et al. Retrospective analysis of the behavioral interview and other preadmission variables to predict licensure examination outcomes in physical therapy. J Allied Health. 2008; 37(2):97-104.

18. Ridgell SD, Lounsbury JW. Predicting academic success: general intelligence, "Big Five" personality traits, and work drive. Coll Stud J 2004; 38(4):607-618.

19. Ferguson E, Sanders A, O'Hehir F, James D.A predictive validity of personal statement and the role of the five factor model of personality in relation to medical training. J Occup Organiz Psych. 2000; 73:321-344.

20. Lieven F, Coestsier P, DeFruyt F, DeMaeseneer J. Medical students' personality characteristics and academic performance: a five-factor model perspective. Med Educ 2002; 36:1050-1056.

21. McLaughlin K, MoutrayM, Muldonn OT. The role of personality and self-efficacy in the selection and retention of successful nursing students: a longitudinal study. J Adv Nsg 2007; 61(2):211-221.

22. Hardigan $P$, Cohen SR. A comparison of learning styles among seven health professions: implications for optometric education. Internet J of Allied Health Sci Pract. 2003; 1(1).

23. Chamorro-Premuzic T, Furnham A. Personality, intelligence, and approaches to learning as predictors of academic performance. Pers Individual Differ 2008; 44:1596-1603.

24. Adejumo O, Brysiewicz P. Coping strategies adopted by baccalaureate nursing student sin a problem-based learning program. Educ Health 1998; 11(3):349-359.

25. Agho AO, Mosley BW, Williams AM. A national survey of current admission practices in selected allied health educational programs. J Allied Health. 1999; 28(1):8-14.

26. Goho J, Blackman A. The effectiveness of academic admission interview: an exploratory meta-analysis. Med Teacher. 2006; 28(4):335-340.

27. Levine SB, Knecht HG, Eisen RG. Selection of physical therapy students: interview methods and academic predictors. $J$ Allied Health. 1986; 15(2):143-151. 
28. Frazer GH, Echternach JL. Response of physical therapy students to stress indicators. J Phys Ther Educ. 1991; 5(2)72-77.

29. Portney LG, Watkins MP. Foundations of Clinical Research: Applications to Practice $2^{\text {nd }}$ edition, Prentice Hall Health, Upper Saddle River, New Jersey, 2000.

30. John OP, Srivastava S. The big five trait taxonomy: history, measurement, and theoretical perspectives. Chapter 4. Handbook of Personality Theory and Research. $2^{\text {nd }}$ edition. Guilford Press, New York/London. 1999. pp102-138.

31. Endler NS,Parker JD.Multidimensional assessment of coping: a critical evaluation. J Pers Soc Psych. 1990; 58(5):844-854.

32. Endler NS, Parker JD. Assessment of multidimensional coping: task, emotion, and avoidance strategies. J Pers Soc Psych. 1994; 6(1):50-60.

33. Grimm LG, Yarnold PR. Reading and Understanding Multivariate Statistics. $5^{\text {th }}$ edition, American Psychological Association, Washington, DC, 1998

34. NPTE Pass Rate Reports. The Federation of State Boards of Physical Therapy. https://www.fsbpt.org/ForCandidatesAndLicensees/NPTE/PassRates/index.asp. Accessed Nov 5, 2010.

35. Linn RL. A century of standardized testing: controversies and pendulum swings. Educ Assess. 2001; 7(1):29038.

36. Zwick R, Greif Green J. New perspectives on the correlation of SAT scores, high school grades and socioeconomic factors. J Educ Meas. 007; 44(1):23-45.

37. Lawlor S, Richman S, Richman CL. The validity of using the SAT as a criterion for black and white students' admission to college. Coll Stud J. 1997; 31(4): 507-516.

38. Slack WV, Porter D. The scholastic aptitude test: a critical appraisal. Harvard Educ Rev. 1980; 50(2):154-175.

39. Leonard DK, Jiang J. Gender bias and the college prediction of the SATs: a cry for despair. Res Higher Educ. 1999;40(4):375-407.

\section{KEY TERMS}

Educational Measurement, Licensure, Physical Therapy 


\section{APPENDIX 1}

\section{Big Five Inventory}

Here are a number of characteristics that may not apply to you. For example, do you agree that you are someone who likes to spend time with others? Please write a number next to each statement to indicate the extent to which you agree or disagree with that statement.

$\begin{array}{cc}\text { Disagree } & \text { Disagree } \\ \text { Strongly } & \text { a little } \\ 1 & 2\end{array}$

I see Myself as Someone Who...

1. is talkative

2. Tends to find fault with others

3. Does a thorough job

4. Is depressed, blue

5. Is original, comes up with new ideas

6. Is reserved

7. Is helpful and unselfish with others

8. Can be somewhat careless

9. Is relaxed, handles stress well

10. Is curious about many different things

11. Is full of energy

12. Starts quarrels with others

13. Is a reliable worker

14. Can be tense

15. Is ingenious, a deep thinker

16. Generates a lot of enthusiasm

17. Has a forgiving nature

18. Tends to be disorganized

19. Worries a lot

20. Has an active imagination

21. Tends to be quiet

22. Is generally trusting

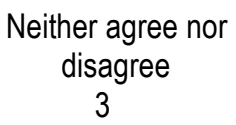

3

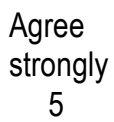

5
23. Tends to be lazy

24. Is emotionally stable, not easily upset

25. Is inventive

26. Has an assertive personality

27. Can be cold and aloof

28. Perseveres until the task is finished

29. Can be moody

30. Values artistic, aesthetic experiences

31. Is sometimes shy, inhibited

32. Is considerate and kind to almost everyone

33. Does things efficiently

34. Remains calm in tense situations

35. Prefers work that is routine

36. Is outgoing, sociable

37. Is sometimes rude to others

38. Make plans and follows through with them

39. Gets nervous easily

40. Likes to reflect, play with ideas

41. Has few artistic interests

42. Likes to cooperate with others

43. Is easily distracted

44. Is sophisticated in art, music, or literature 